\title{
Active and stable platinum/ionic liquid/carbon nanotube electrocatalysts for oxidation of methanol
}

\author{
Guan-Lin Lin ${ }^{1}$, Arun Prakash Periasamy ${ }^{1}$, Zih-Yu Shih $^{1}$, and Huan-Tsung Chang* ${ }^{1}$ \\ ${ }^{1}$ Department of Chemistry, National Taiwan University, 1, Section 4, Roosevelt Road, Taipei 106, Taiwan \\ *Corresponding author's e-mail address: changht@ntu.edu.tw
}

Published online: 9 October 2014 (version 1); 29 July 2015 (version 2)

Cite as: Lin et al., ScienceOpen Research 2015 (DOI: 10.14293/S2199-1006.1.SOR-CHEM.AYZQJS.v2)

Reviewing status: Please note that this article is under continuous review. For the current reviewing status and the latest referee's comments please click here or scan the QR code at the end of this article.

Primary discipline: Chemistry

Keywords: Imidazolium ionic liquids, Platinum nanoparticles, Carbon nanotubes, Methanol oxidation reaction, Anode catalyst

\begin{abstract}
Platinum (Pt) nanoparticles (NPs) on carbon nanotubes (CNTs) have been prepared from $\mathrm{PtCl}_{6}{ }^{2-}$ ions through a facile ionic liquid (IL)-assisted method and used for methanol oxidation. 1-Butyl-3-methylimidazolium (BMIM) with four different counter ions $\left(\mathrm{PF}_{6}^{-}, \mathrm{Cl}^{-}, \mathrm{Br}^{-}\right.$, and $\left.\mathrm{I}^{-}\right)$has been tested for the preparation of Pt/IL/CNT nanohybrids, showing the counter ions of ILs play an important role in the formation of small sizes of Pt NPs. Only [BMIM] $\left[\mathrm{PF}_{6}\right]$ and [BMIM] [Cl] allow reproducible preparation of $\mathrm{Pt} / \mathrm{IL} / \mathrm{CNT}$ nanohybrids.

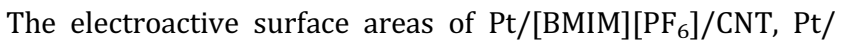
[BMIM][Cl]/CNT, Pt/CNT, and commercial Pt/C electrodes are 62.8, 101.5, 78.3, and $87.4 \mathrm{~m}^{2} \mathrm{~g}^{-1}$, respectively. The Pt/ [BMIM][Cl]/CNT nanohybrid-modified electrodes provide higher catalytic activity (251.0 $\mathrm{A} \mathrm{g}^{-1}$ ) at a negative onset potential of $-0.60 \mathrm{~V}$ than commercial $\mathrm{Pt} / \mathrm{C}$-modified ones do (133.5 $\mathrm{A} \mathrm{g}^{-1}$ ) at $-0.46 \mathrm{~V}$. The Pt/[BMIM][Cl]/CNT electrode provides the highest ratio (4.52) of forward/reverse oxidation current peak, revealing a little accumulation of carbonaceous residues.
\end{abstract}

\section{INTRODUCTION}

Platinum $(\mathrm{Pt})$ nanomaterials with various morphologies, large surface areas, and high surface energies have been widely used as catalysts for enhanced methanol oxidation reaction (MOR) in direct methanol fuel cells (DMFCs) $[1,2]$. In order to enhance the efficiency of DMFCs and to accelerate the electron transfer rate, carbon nanotubes (CNTs) with high specific surface areas, electrical conductivities, and chemical stability have been used as supports for the preparation of $\mathrm{Pt}$ nanoparticles (NPs)/CNT nanohybrids [3-7]. However, pristine CNTs have insufficient binding sites to anchor Pt ions (precursors) and NPs, which lead to poor dispersion, aggregation of NPs [8], inefficient catalytic activity, poor reproducibility, and poor durability of Pt NPs/CNT nanohybrids.

In order to produce more efficient Pt NPs/CNT nanohybrids, functional CNTs with greater binding sites and surface anchoring groups are usually used [9]. Acid-oxidation is a common approach to produce CNTs with greater binding sites (CO, $\mathrm{COH}$, and $\mathrm{COOH}$ groups) that can anchor great amounts of Pt ions and Pt NPs [10, 11]. However, this method typically leads to uneven distribution of surface functional groups as well as severe structural damage to CNTs. Strong acids used to treat CNTs at elevated temperature are a concern. Alternatively, electrochemical oxidation of CNTs at their defect sites is used to produce quinonyl, carboxyl, or hydroxyl groups on their surfaces [12-14]. Chemical modification of CNTs with water-soluble polymers, quaternary ammonium salts, surfactants, and polyoxoanions has become popular for preparation of functional CNTs, mainly because it is easy to purify and disperse the functional CNTs in aqueous solution [15]. However changes in the aromatic structures of CNTs sometimes occurs [16]. With various degrees of $\pi$-conjugates $(C=C)$ on their surfaces, aromatic compounds such as pyrene have been conjugated with CNTs through $\pi-\pi$ stacking. Although modification of CNTs can be achieved without altering their structure under mild reaction conditions [17], weak $\pi-\pi$ stacking force between molecules and CNTs might cause reproducibility and durability problems. It has been shown that Pt NPs tend to get deposited on the defect sites and boundaries of the CNTs, which allows the as-deposited Pt NPs to be surrounded with more oxygen containing functional groups that favors the facile electron and proton transport during the MOR [18]. The inner and outer surfaces of CNTs and grooves at the junction of adjacent CNTs act as chemisorption sites for the Pt NPs [19]. The other factors that affected the distribution and deposition of Pt NPs on the surfaces of CNTs are interaction between the Pt ions and the functional groups, properties of CNTs, and the functional group densities on the outer walls of CNTs [20].

Ionic liquids (ILs) have been found useful for the modification of CNTs [1, 21] as they have excellent properties of good chemical and thermal stability, negligible vapor pressure, good electrical conductivity, and a wide electrochemical window 
$[22,23]$. In addition, ILs are also useful solvents and stabilizers for the preparation of various metal NPs, mainly because of having high intrinsic charges that allow them to stabilize metal NPs through electrostatic attractions [24-26]. Having such excellent properties to stabilize CNTs and Pt NPs [27], it is worthy to prepare Pt NPs/CNT nanohybrids in the presence of ILs.

To prepare Pt NPs/CNT nanohybrids, 1-butyl-3-methylimidazolium (BMIM)-based ILs with various counter ions were tested, including $[\mathrm{BMIM}]\left[\mathrm{PF}_{6}\right],[\mathrm{BMIM}][\mathrm{Cl}],[\mathrm{BMIM}][\mathrm{Br}]$, and [BMIM][I]. The BMIM based ILs were adsorbed onto the surfaces of CNTs to provide great amount of surface functional groups on their surfaces to stabilize $\mathrm{Pt}^{4+}$ ions that were then reduced to form well distributed Pt NPs by ethylene glycol. The IL on the CNTs also provided great amounts of positive charges that prevented aggregation of the as-prepared $\mathrm{Pt}$ NPs/CNT nanohybrids. The as-prepared Pt/[BMIM][Cl]/CNT nanohybrids possessed enhanced electrocatalytic activity and stability toward MOR when compared with the nanohybrids prepared without ILs, showing their great potential in DMFCs.

\section{EXPERIMENTAL}

\section{Materials}

Multiwalled carbon nanotubes (MWCNTs, $>90 \%$ purity) as bundles with 10-30 $\mathrm{nm}$ in diameter were purchased from Seedchem Company Pty. Ltd. (Melbourne, Australia). [BMIM] $\left[\mathrm{PF}_{6}\right] \quad(\geq 98.0 \mathrm{wt} \%)$ and $[\mathrm{BMIM}][\mathrm{Cl}](\geq 98.0 \mathrm{wt} \%)$ were obtained separately from Acros Organics (Geel, Belgium) and Tokyo Chemical Industry (Tokyo, Japan). $N, N$-dimethylformamide (DMF, $\geq 99.8$ wt\%) was purchased from Sigma-Aldrich (Milwaukee, WI). Ethylene glycol ( $\geq 99.9$ wt\%) was purchased from J. T. Baker (Phillipsburg, NJ, USA). [BMIM][Br] ( $\geq 99.0 \mathrm{wt} \%$ ) and platinum on activated carbon $(40 \mathrm{wt} \% \mathrm{Pt})$ were obtained from Alfa Aesar (Ward Hill, MA, USA). [BMIM][I] ( $\geq 98.0 w t \%$ ) was purchased from UniRegion Bio-Tech (Taipei, Taiwan). Potassium hexachloroplatinate (IV) was obtained from J \& J Materials (Neptune City, New Jersey). Methanol ( $\geq 99.8$ wt\%) was purchased from Sigma (St. Louis, MO, USA). Nafion 117 (5 wt\%) was purchased from Fluka (Buchs, Switzerland). Screen-printed carbon electrodes (No. SE101-GK) were obtained from Zensor R\&D (Taichung, Taiwan). Double distilled water (18.2 M $\Omega$-cm) from a Milli-Q ultrapure system (London, UK) was used throughout this study.

\section{Preparation of Pt/ILs/CNT nanohybrids}

Four ILs, including [BMIM][PF 6 , [BMIM][Cl], [BMIM][Br], and [BMIM][I], were used separately to prepare Pt/ILs/CNT nanohybrids. In a typical procedure, CNT $(0.4 \mathrm{mg})$ and [BMIM] $\left[\mathrm{PF}_{6}\right](400 \mu \mathrm{L}, 4 \%)$ were mixed with DMF to obtain a final volume of $10.0 \mathrm{~mL}$. We found that sonicating the mixture for longer time $(>5 \mathrm{~min})$ did not increase the dispersing ability of CNTs. To avoid sonication-induced damage to the CNTs, 5 min sonication time was found to be optimal for our study. The sonication power and frequency were kept low and cold water with a surfactant was used in the sonicator bath to avoid heat-induced damage to the CNTs. The solution was thus subjected to sonication for $5 \mathrm{~min}$ and then excess DMF was removed through centrifugation at a relative centrifuge force (RCF) of $7370 \mathrm{~g}$ for $10 \mathrm{~min}$. The black precipitates were added to a mixture of ethylene glycol $(5.7 \mathrm{~mL})$ and ultrapure water $(2.3 \mathrm{~mL})$. The mixture was subjected to sonication for $5 \mathrm{~min}$ and then $\mathrm{K}_{2} \mathrm{PtCl}_{6}(2.0 \mathrm{~mL}, 0.6 \mathrm{mM})$ was added. The reaction mixture was kept at $115{ }^{\circ} \mathrm{C}$ for $1 \mathrm{~h}$ to form Pt/ILs/ CNT nanohybrids. The as-prepared Pt/ILs/CNT nanohybrids were finally purified through sonication for $5 \mathrm{~min}$ and four cycles of centrifugation (RCF $7370 \mathrm{~g}, 10 \mathrm{~min}$ )/wash (ultrapure water, $4 \times 10 \mathrm{~mL}$ ).

\section{Characterization}

Transmission electron microscopy (TEM) and high-resolution TEM (HRTEM) images of as-prepared Pt/ILs/CNT nanohybrids were recorded using JEOL JSM-1230 (Hitachi, Tokyo, Japan) and FEI Tecnai-G2-F20 (GCEMarket, NJ, USA) systems operating at $200 \mathrm{kV}$, respectively. Energy-dispersive X-ray spectrometer (EDS) equipped with a Hitachi S-4800 field emission scanning electron microanalyzer (Hitachi, Tokyo, Japan) was applied to determine the composition of the asprepared Pt/ILs/CNT nanohybrids. The X-ray diffraction (XRD) patterns of the as-prepared Pt/ILs/CNT nanohybrids were recorded using a PANalytical X'Pert PRO diffractometer (Almelo, Netherlands) with $\mathrm{Cu} \mathrm{K} \alpha$ radiation $(\lambda=0.15418 \mathrm{~nm})$. X-ray photoelectron spectroscopy (XPS) measurement was conducted using a VG ESCA210 electron spectroscope from VG Scientific (West Sussex, UK) to determine Pt oxidation state in the as-prepared Pt/ILs/CNT nanohybrids. The binding energy (BE) of carbon was used as an internal reference to eliminate the charging effect. The samples for XPS measurements were prepared by depositing aliquots of the as-prepared Pt/ILs/ CNT nanohybrids onto $\mathrm{Si}$ substrates and then the solvents were evaporated at ambient temperature $\left(25^{\circ} \mathrm{C}\right)$ and pressure. An Elan 6000 inductively coupled plasma mass spectrometer (ICP-MS) from Perkin-Elmer (Wellesley, MA, USA) was employed to determine $\mathrm{Pt}$ contents in the as-prepared Pt/ILs/CNT nanohybrids. Prior to ICP-MS measurements, the as-prepared Pt/ILs/CNT nanohybrids were dissolved in $2 \% \mathrm{HNO}_{3}$.

\section{Fabrication of electrodes and electrocatalytic analysis}

Aliquots $(5 \mu \mathrm{L})$ of the as-synthesized Pt/ILs/CNT nanohybrids solutions were dropped separately onto clean screen-printed carbon electrodes (diameter: $3 \mathrm{~mm}$ ). After the electrodes were air-dried for $1 \mathrm{~h}$ at ambient temperature, Nafion solution $(0.5 \%, 1 \mu \mathrm{L})$ was placed onto each of the electrodes. Threeelectrode electrochemical cells were fabricated using the modified electrode as a working electrode, a Pt wire as an auxiliary electrode, and an $\mathrm{Ag} / \mathrm{AgCl}$ electrode as a reference electrode. The electrocatalytic activities of the as-synthesized 
Pt/ILs/CNT nanohybrids were measured using a $\mathrm{CH}$ Instruments (CHI) 760D electrochemical workstation (Austin, TX, USA). Cyclic voltammetry (CV) measurements in $0.5 \mathrm{M} \mathrm{KOH}$ with or without containing $0.5 \mathrm{M}$ methanol were conducted over the potential range from -1.0 to $0.2 \mathrm{~V}$ at a scan rate of $100 \mathrm{mV} \mathrm{s}^{-1}$. As a control, commercial Pt/C NPs and assynthesized Pt/CNT nanohybrids prepared without ILs were used to prepare working electrodes under the same conditions. All electrochemical data were recorded over 50 reproducible cycles. The chronoamperometric measurements for durability tests were conducted in $0.5 \mathrm{M} \mathrm{KOH}$ containing $0.5 \mathrm{M}$ methanol at a fixed potential of $-0.1 \mathrm{~V}$ for $20,000 \mathrm{~s}$.

\section{RESULTS AND DISCUSSION}

\section{Formation and characterization of Pt/ILs/CNT nanohybrids}

CNTs were stabilized in the aqueous solutions through the $\pi-\pi$ interaction of CNTs with BMIM group of the ILs. $\mathrm{PtCl}_{6}{ }^{2-}$ ions were then adsorbed on the cationic surfaces of the CNTs through electrostatic interactions [28]. The adsorbed $\mathrm{PtCl}_{6}{ }^{2-}$ ions were reduced by ethylene glycol (reducing agent) to form Pt NPs on the surfaces of CNTs. Having a weaker reducing strength than $\mathrm{NaBH}_{4}$ and a capability for rapid and homogenous in-situ generation of reducing species, ethylene glycol allowed better control of the particle growth, leading to the formation of a fairly uniform Pt NPs on the surfaces of CNTs $[29,30]$. The Pt NPs are formed through reactions (1) and (2) [31]:

$$
\begin{aligned}
& \mathrm{HOCH}_{2} \mathrm{CH}_{2} \mathrm{OH}_{2} \rightarrow \mathrm{CH}_{3} \mathrm{CHO}+\mathrm{H}_{2} \mathrm{O} \\
& \underset{2 \mathrm{CH}_{3} \mathrm{CHO}+\left(\mathrm{PtCl}_{6}\right)^{2-}+6 \mathrm{OH}^{-}}{\rightarrow 2 \mathrm{CH}_{3} \mathrm{COO}^{-}+\mathrm{Pt}+6 \mathrm{Cl}^{-}+4 \mathrm{H}_{2} \mathrm{O}}
\end{aligned}
$$

Figure $1 \mathrm{~A}$ and $1 \mathrm{~B}$ shows the TEM images of $\mathrm{Pt} /[\mathrm{BMIM}]\left[\mathrm{PF}_{6}\right] /$ CNT and Pt/[BMIM][Cl]/CNT nanohybrids, respectively. Pt NPs are uniformly distributed on the surfaces of CNTs. As displayed in the histogram provided in the inset of Figure 1A, greater amount and better distribution (36\%) of Pt NPs with a diameter of $2.8 \mathrm{~nm}$ are formed on the CNT surface when using $[\mathrm{BMIM}]\left[\mathrm{PF}_{6}\right]$. The ring patterns of selected-area electron diffraction (SAED) are displayed in the insets to Figure $1 \mathrm{~A}$ and $1 \mathrm{~B}$, respectively, revealing the crystalline structures of $\mathrm{Pt}$ (111). HRTEM images of Pt/[BMIM] $\left[\mathrm{PF}_{6}\right] / \mathrm{CNT}$ and Pt/[BMIM] $[\mathrm{Cl}] / \mathrm{CNT}$ nanohybrids in Figure $1 \mathrm{C}$ and $1 \mathrm{D}$, respectively, clearly show highly dispersed Pt NPs on the CNT surface. Pt NPs with small size $(2.6 \mathrm{~nm})$ and greater distribution (38\%) are formed on the CNT surface when using [BMIM] $\left[\mathrm{PCl}_{6}\right]$ (inset to Figure 1B). The lattice spacing of $d_{111}$ for the Pt NPs is $0.22 \mathrm{~nm}$ [32]. The average diameters of Pt NPs (200 counts) in the Pt/[BMIM] $\left[\mathrm{PF}_{6}\right] / \mathrm{CNT}$ and $\mathrm{Pt} /[\mathrm{BMIM}][\mathrm{Cl}] / \mathrm{CNT}$ nanohybrids are $2.8 \pm 0.3$ and $2.6 \pm 0.2 \mathrm{~nm}$, respectively.

Figure S1 displays that the Pt/CNT, Pt/[BMIM] $\left[\mathrm{PF}_{6}\right] / \mathrm{CNT}$, and $\mathrm{Pt} /[\mathrm{BMIM}][\mathrm{Cl}] / \mathrm{CNT}$ nanohybrids all provide the diffraction peaks at $39.5^{\circ}$ and $45.7^{\circ}$ that are assigned to face central cubic Pt planes (111) and (200), respectively, in reference to JCPDS card no. 87-0646 [33]. The peaks at $25.9^{\circ}, 42.7^{\circ}$, and $54.2^{\circ}$ correspond to the (002), (100), and (004) planes of graphitized CNTs, in reference to JCPDS card No. 75-1621 [33]. The results reveal that the as-synthesized nanohybrids contain pure crystalline Pt and CNTs [25]. The XPS spectra depicted in Figure $2 \mathrm{~A}$ and $2 \mathrm{~B}$ show a doublet of $\mathrm{Pt}_{4 \mathrm{f}}$ peaks at $71.6 \mathrm{eV}$ $\left(4 \mathrm{f}_{7 / 2}\right)$ and $74.8 \mathrm{eV}\left(4 \mathrm{f}_{5 / 2}\right)$, respectively, which correspond to the metallic Pt [34]. After deconvolution, six peaks were identified as shown in the dotted curves [29]. The $4 f_{7 / 2}$ peak at $72.4 \mathrm{eV}$ with a $4 \mathrm{f}_{5 / 2}$ component at $75.6 \mathrm{eV}$ is attributed to the Pt (II) chemical states of PtO or Pt $(\mathrm{OH})_{2}$ [34]. While the $4 \mathrm{f}_{7 / 2}$ peak at $73.4 \mathrm{eV}$ with a $4 \mathrm{f}_{5 / 2}$ component at $76.8 \mathrm{eV}$ is attributed to the +4 oxidation state of Pt. Figure $2 \mathrm{C}$ and $2 \mathrm{D}$ shows the $C_{1 s}$ spectra, which exhibits a main peak at $284.7 \mathrm{eV}$ that is assigned for the $\mathrm{C}_{1 \mathrm{~s}}$ of the $\mathrm{sp}^{2}$-hybryidized graphitic carbon [35]. A peak at $285.3 \mathrm{eV}$ is assigned to $\mathrm{sp}^{3}$-hybridized carbon atoms that are found to be same as that of diamondlike carbon [35]. We note that these two peaks are observed in amorphous carbons, and their relative intensity correlates with the degree of graphitization [36]. Peaks with higher binding energies located at 286.0, 287.5, and $289.4 \mathrm{eV}$ are assigned to $\mathrm{C}-\mathrm{O}-$ (e.g., alcohol, ether), $>\mathrm{C}=\mathrm{O}$ (ketone, aldehyde), and $-\mathrm{COO}-$ (carboxylic acid, ester) functional groups, respectively [33, 35]. The peak at $286.7 \mathrm{eV}$ is assigned to $\mathrm{C}-\mathrm{N}$ group of BMIM [37]. We note that the electronegative oxygen atoms induce the formation of more positive charge on a carbon atom. The bonding configurations (Figure $2 \mathrm{E}$ and $2 \mathrm{~F}$ )

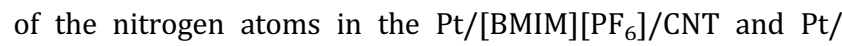
[BMIM][Cl]/CNT nanohybrids were also fitted. The peak at $399.8 \mathrm{eV}$ in the $\mathrm{N}_{1 \mathrm{~s}}$ spectrum corresponds to pyrrole-like nitrogen. When carbon atoms in the CNT surface are substituted with nitrogen atoms in the form of "graphitic" nitrogen, the corresponding peak is located at $401.5 \mathrm{eV}$ $[2,38-40]$. The functionalization of CNTs with nitrogencontaining materials is beneficial to enhance the dispersion of Pt NPs on the CNTs due to a strong coordinative interaction between nitrogen atoms and Pt NPs $[6,12,13]$.

\section{Electrocatalytic activities of Pt/ILs/CNT nanohybrid-modified electrodes}

Prior to testing the electroactivity of the as-prepared Pt/ILs/ CNT nanohybrids for MOR, we estimated their electroactive surface areas (EASA, $\mathrm{m}^{2} \mathrm{~g}^{-1}$ ) by conducting CV measurement [41]. The CVs of Pt/ILs/CNT nanohybrid-modified electrodes at a scan rate of $100 \mathrm{mV} \mathrm{s}^{-1}$ are displayed in Figure 3A. The EASA of each electrode was calculated using equation (3):

$$
\mathrm{EASA}=Q /(0.21 \times[\mathrm{Pt}])
$$

where [Pt] represents the $\mathrm{Pt}$ loading $\left(\mathrm{mg} \mathrm{cm}^{-2}\right)$ in the electrode. EASA was calculated from integrating the charges associated with the hydrogen adsorption-desorption peaks 

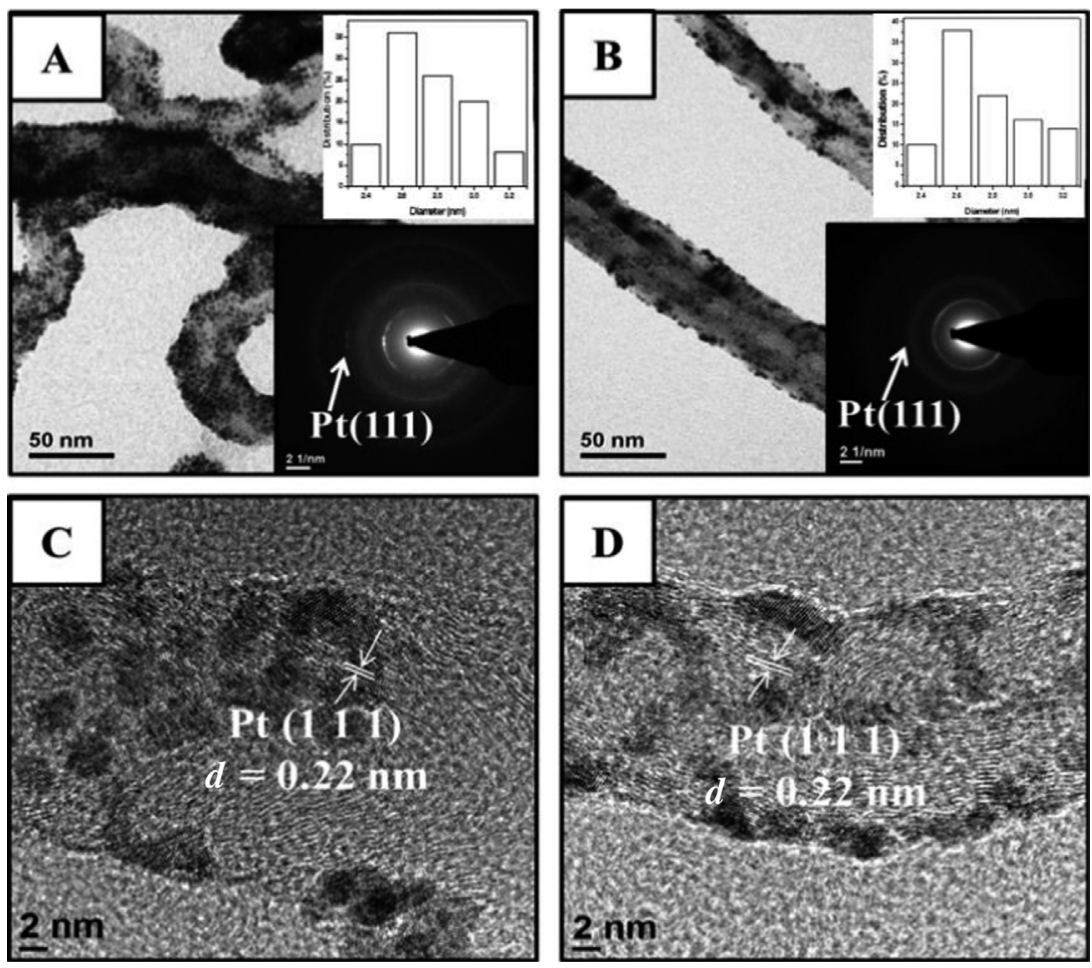

Figure 1. TEM images ( $A$ and $B$ ) and HRTEM images ( $C$ and $D)$ of $P t /[B M I M]\left[P F_{6}\right] / C N T$ and $P t /[B M I M][C l] / C N T$ nanohybrids. Inset to (A) and $(B)$ : their corresponding SAED patterns and the histograms of Pt particles size distribution.

$\left(Q, \mathrm{mC} \mathrm{cm}^{-2}\right)$, assuming $210 \mu \mathrm{C} \mathrm{cm}^{-2}$ needed for a monolayer of $\mathrm{H}$ as-atoms in Figure 3A [42]. The EASAs of as-prepared $\mathrm{Pt} /[\mathrm{BMIM}]\left[\mathrm{PF}_{6}\right] / \mathrm{CNT}, \mathrm{Pt} /[\mathrm{BMIM}][\mathrm{Cl}] / \mathrm{CNT}$ and Pt/CNT nanohybrids, and commercial Pt/C NPs are 62.8, 101.5, 78.3, and $87.4 \mathrm{~m}^{2} \mathrm{~g}^{-1}$, respectively. The results reveal that the counter ions of ILs affected the adsorbed amounts of Pt NPs, mainly because the species of anions, cations, and the length of the lateral alkyl groups on the heterocyclic rings affect the physicochemical properties of ILs [27]. Since $\mathrm{PF}_{6}{ }^{-}$relative to $\mathrm{Cl}^{-}$has higher steric effect, it is more difficult for $\mathrm{PtCl}_{6}{ }^{2-}$ ions to access the surface of CNTs adsorbed with [BMIM] $\left[\mathrm{PF}_{6}\right]$, as a result less amounts of Pt NPs with a smaller EASA value are formed when using $[\mathrm{BMIM}]\left[\mathrm{PF}_{6}\right]$. Further, the EASA value $\left(101.5 \mathrm{~m}^{2} \mathrm{~g}^{-1}\right)$ of Pt/[BMIM][Cl]/CNT is higher than that of IL (1-octyl-3-methylimidazolium $\mathrm{PF}_{6}$ ) supported $\mathrm{Pt}_{0.17} \mathrm{Cu}_{0.83} /$ graphene (75.6 $\left.\mathrm{m}^{2} \mathrm{~g}^{-1}\right)$, Pt/graphene (49.4 $\left.\mathrm{m}^{2} \mathrm{~g}^{-1}\right)$, $\mathrm{Pt}_{0.17} \mathrm{Cu}_{0.83}$ /carbon black (27.6 $\left.\mathrm{m}^{2} \mathrm{~g}^{-1}\right)$, Pt/carbon black (10.1 $\mathrm{m}^{2} \mathrm{~g}^{-1}$ ) [43], PtRu/CNTs-PIL (91.2 $\mathrm{m}^{2} \mathrm{~g}^{-1}$ ), and Pt/ CNTs-PIL (71.4 $\mathrm{m}^{2} \mathrm{~g}^{-1}$ ) [44] catalysts, respectively. Figure 3B shows the CVs of as-prepared $\mathrm{Pt} /[\mathrm{BMIM}]\left[\mathrm{PF}_{6}\right] / \mathrm{CNT}, \mathrm{Pt} /$ [BMIM][Cl]/CNT, Pt/CNT nanohybrids, and commercial Pt/C NPs in $0.5 \mathrm{M} \mathrm{KOH}$ containing $0.5 \mathrm{M}$ methanol at a scan rate of $100 \mathrm{mV} \mathrm{s}^{-1}$. The Pt/[BMIM][Cl]/CNT nanohybrid-modified electrode exhibited a mass activity of $251.0 \mathrm{~A} \mathrm{~g}^{-1}$ for MOR, which is higher than that (126.9 $\left.\mathrm{A} \mathrm{g}^{-1}\right)$ of the Pt/[BMIM] $\left[\mathrm{PF}_{6}\right] / \mathrm{CNT}$ nanohybrid-modified electrode. Besides, the mass activity of $251.0 \mathrm{~A} \mathrm{~g}^{-1}$ for the Pt/[BMIM][Cl]/CNT nanohybrid-modified electrode in alkaline solution $(0.5$ $\mathrm{M} \mathrm{KOH})$ is higher than that (242.3 $\mathrm{A} \mathrm{g}^{-1}$, and $155.7 \mathrm{~A} \mathrm{~g}^{-1}$ ) for the PtRu/CNTs-PIL and Pt/CNTs-PIL modified electrodes [44], respectively in the acidic solution $\left(0.5 \mathrm{M} \mathrm{H}_{2} \mathrm{SO}_{4}\right)$, showing that higher EASA and alkaline conditions are essential to provide higher mass activity for MOR. It has also been reported that the polarization characteristics of MOR at the unsupported Pt black in alkaline solution is one order higher than that in the acidic solution [45]. The onset potential of MOR on the Pt/[BMIM][Cl]/CNT nanohybrid-modified electrode occurred at $-0.60 \mathrm{~V}$ (vs. $\mathrm{Ag} / \mathrm{AgCl}$ ), which is more negative than those of as-prepared $\mathrm{Pt} /[\mathrm{BMIM}]\left[\mathrm{PF}_{6}\right] / \mathrm{CNT}$ nanohybrids $(-0.50 \mathrm{~V}), \mathrm{Pt} / \mathrm{CNT}(-0.47 \mathrm{~V})$, commercial Pt/C catalyst $(-0.46 \mathrm{~V})$, and $\mathrm{Pd} / \mathrm{Pt}(-0.50 \mathrm{~V})$ [46]. It is likely attributed to the stronger adsorption of chlorine on the $\mathrm{Pt}$ (100) surface than that on the $\operatorname{Pt}(111)$ surface due to the lower work function of $\operatorname{Pt}(100)$ surface [47]. The result reveals that $\mathrm{Pt} /[\mathrm{BMIM}][\mathrm{Cl}] / \mathrm{CNT}$ nanohybrid-modified electrode relative to other tested electrodes provided greater electrooxidation activity toward the MOR [48]. The cathodic oxide reduction peak for the $\mathrm{Pt} /[\mathrm{BMIM}][\mathrm{Cl}] / \mathrm{CNT}$ nanohybrids occurred at $-0.48 \mathrm{~V}$ (Figure $3 \mathrm{~A}$ ), which is at least $0.05 \mathrm{~V}$ higher than other tested catalysts, showing their less favorable formation of Pt-OH [49]. A fast charge transfer through the Pt/ $[\mathrm{BMIM}][\mathrm{Cl}] / \mathrm{CNT}$ nanohybrids resulted in the high electrocatalytic activity. Small size (large surface areas) Pt NPs in the $\mathrm{Pt} /[\mathrm{BMIM}][\mathrm{Cl}] / \mathrm{CNT}$ nanohybrids improved their electrocatalytic 

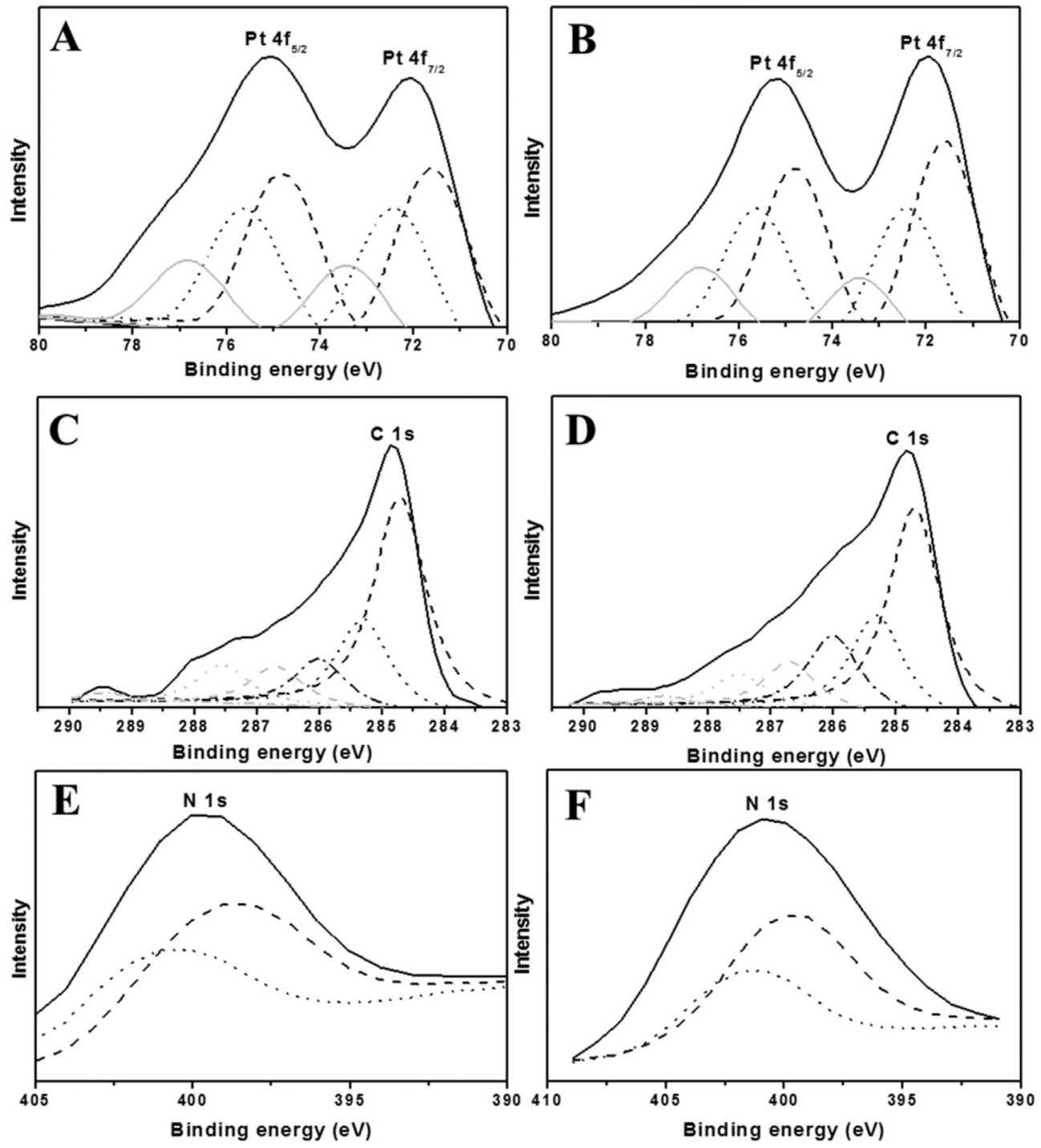

Figure 2. XPS spectra displaying the $\mathrm{Pt}_{4 \mathrm{f}}(\mathrm{A}$ and $\mathrm{B}), \mathrm{C}_{1 \mathrm{~s}}(\mathrm{C}$ and $\mathrm{D})$, and $\mathrm{N}_{1 \mathrm{~s}}\left(\mathrm{E}\right.$ and $\mathrm{F}$ ) energy levels of the $\mathrm{Pt} /[\mathrm{BMIM}]\left[\mathrm{PF} \mathrm{F}_{6}\right] / C N T(A, C$, and $E)$ and $\mathrm{Pt} /[\mathrm{BMIM}][\mathrm{Cl}] / \mathrm{CNT}(\mathrm{B}, \mathrm{D}$, and $\mathrm{F})$ nanohybrids.

activity toward MOR [50]. The voltammograms of Pt/CNT nanohybrids and commercial $\mathrm{Pt} / \mathrm{C}$ are very similar, providing mass activities of 132.5 and $133.5 \mathrm{~A} \mathrm{~g}^{-1}$, respectively for MOR. The higher mass activity and a lower onset potential obtained in the $\mathrm{Pt} /[\mathrm{BMIM}][\mathrm{Cl}] / \mathrm{CNT}$ nanohybrid-electrode reveal that the $\mathrm{Pt} /[\mathrm{BMIM}][\mathrm{Cl}] / \mathrm{CNT}$ nanohybrids provided greater electrooxidation activity toward MOR. During the MOR process, the adsorption of intermediate carbonaceous species on the catalyst's surface would lead to "catalyst poisoning." The ratio of the forward oxidation current peak $\left(I_{\mathrm{f}}\right)$ to the reverse current peak $\left(I_{\mathrm{b}}\right), I_{\mathrm{f}} / I_{\mathrm{b}}$, is an important index of the catalyst tolerance to the accumulation of carbonaceous species. A higher $I_{\mathrm{f}} / I_{\mathrm{b}}$ ratio indicates that methanol is efficiently oxidized to $\mathrm{CO}_{2}$ with a little accumulation of carbonaceous residues at the catalyst surface [51-54]. The $I_{\mathrm{f}} / I_{\mathrm{b}}$ values of as-prepared catalysts were calculated to be 3.5 for $\mathrm{Pt} /[\mathrm{BMIM}]\left[\mathrm{PF}_{6}\right] / \mathrm{CNT}, 4.5$ for $\mathrm{Pt} /$ [BMIM][Cl]/CNT, 2.8 for Pt/CNT, and 3.1 for commercial $\mathrm{Pt} / \mathrm{C}$. A higher $I_{\mathrm{f}} / I_{\mathrm{b}}$ value of $\mathrm{Pt} /[\mathrm{BMIM}][\mathrm{Cl}] / \mathrm{CNT}$ catalyst than other reported catalysts $(0.83$ for Pt/CCG [30], 0.72 for Pt/ MWCNT [30], and 1.75 for $\mathrm{Pt}_{0.17} \mathrm{Cu}_{0.83} /$ graphene [32]) reveals that oxidation of methanol occurs more effectively. The enhanced electrocatalytic activity and stability of Pt/ [BMIM][Cl]/CNT nanohybrids for MOR are probably due to the strong interactions between [BMIM][Cl] and Pt NPs, which inhibits the formation of chemisorbed carbonaceous species [55]. To test the important role played by the counter ions in determining the electroactivity, the Pt/ILs/CNT nanohybrids prepared using [BMIM][Br] and [BMIM][I] were separately investigated (Figure S2A and S2B). The MOR current densities ( 8.5 and $9.9 \mathrm{~mA} \mathrm{~cm}^{-2}$ ) provided by the two electrodes were lower than that of the Pt/[BMIM] 

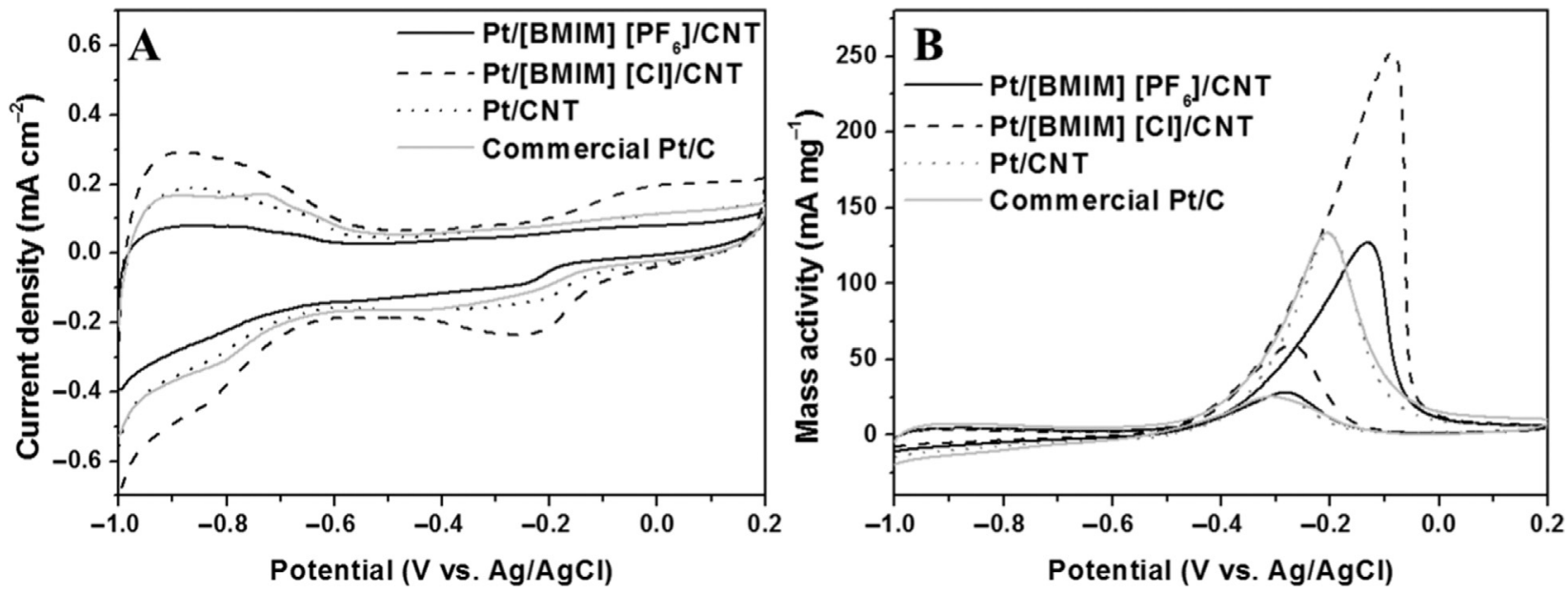

Figure 3. (A) EASA and (B) CV curves of Pt/[BMIM][PF $\left.{ }_{6}\right] / C N T, P t /[B M I M][C I] / C N T, P t / C N T$ nanohybrids, and commercial Pt/C NPs electrodes. (A) EASA was estimated by integrating the charges associated with hydrogen desorption in $0.5 \mathrm{M} \mathrm{KOH}$. (B) $\mathrm{CV}$ was recorded in $0.5 \mathrm{M} \mathrm{KOH}$ containing $0.5 \mathrm{M}$ methanol. Scan rate: $100 \mathrm{mV} \mathrm{s}^{-1}$.

[Cl]/CNT electrode. Having higher viscosity than [BMIM][Cl], [BMIM][Br], and [BMIM][I] were difficult to be dispersed on the CNT surface, leading to greater aggregation of Pt NPs. As a result, poor reproducibility was obtained.

The CVs displayed in Figure S3A and 3B reveal that the EASA

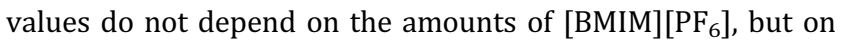
the amount of [BMIM][Cl]. [BMIM][Cl] possessing hydrophilic property can adsorb $\mathrm{H}$ atoms more strongly than [BMIM] $\left[\mathrm{PF}_{6}\right]$ [56]. In other words, direct MOR processes would occur favorably on the as-prepared $\mathrm{Pt} /[\mathrm{BMIM}][\mathrm{Cl}] / \mathrm{CNT}$ nanohybrid-modified electrodes, leading to greater catalytic activity. As expected, Figure $\mathrm{S} 4 \mathrm{~A}$ and $4 \mathrm{~B}$ shows that the amount of $[\mathrm{BMIM}]\left[\mathrm{PF}_{6}\right]$ in the $\mathrm{Pt} /[\mathrm{BMIM}]\left[\mathrm{PF}_{6}\right] / \mathrm{CNT}$ nanohybrids and that of $[\mathrm{BMIM}][\mathrm{Cl}]$ in the $\mathrm{Pt} /[\mathrm{BMIM}][\mathrm{Cl}] / \mathrm{CNT}$ nanohybrids does not and does affect their mass activities, respectively. Upon increasing the amount of [BMIM][Cl], greater amounts of Pt NPs were formed, leading to greater EASA values and thus mass activity. The optimum loading volume of [BMIM][Cl] was found to be $400 \mu \mathrm{L}$. Further increases in the amount of [BMIM][Cl] are not suggested, mainly because greater amounts of Pt NPs were not formed [11].

Further evaluation of the catalytic durability of as-prepared $\mathrm{Pt} /[\mathrm{BMIM}]\left[\mathrm{PF}_{6}\right] / \mathrm{CNT}, \mathrm{Pt} /[\mathrm{BMIM}][\mathrm{Cl}] / \mathrm{CNT}, \mathrm{Pt} / \mathrm{CNT}$ nanohybrids, and commercial Pt/C NPs electrodes was performed by chronoamperometry in $0.5 \mathrm{M} \mathrm{KOH}$ containing $0.5 \mathrm{M}$ methanol at $-0.1 \mathrm{~V}$ vs. $\mathrm{Ag} / \mathrm{AgCl}$. As shown in Figure 4 , an initial decay of the current density occurred, mainly because of loss of surface active sites as a result of adsorption of intermediate species on the catalyst surface [57]. The as-

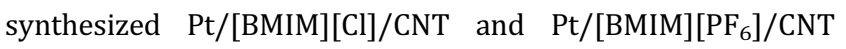
catalysts provided greater stability (at least sweeping for 20,000 seconds) and higher current densities than the rest. These results reveal that the coordination of Pt with BMIM on

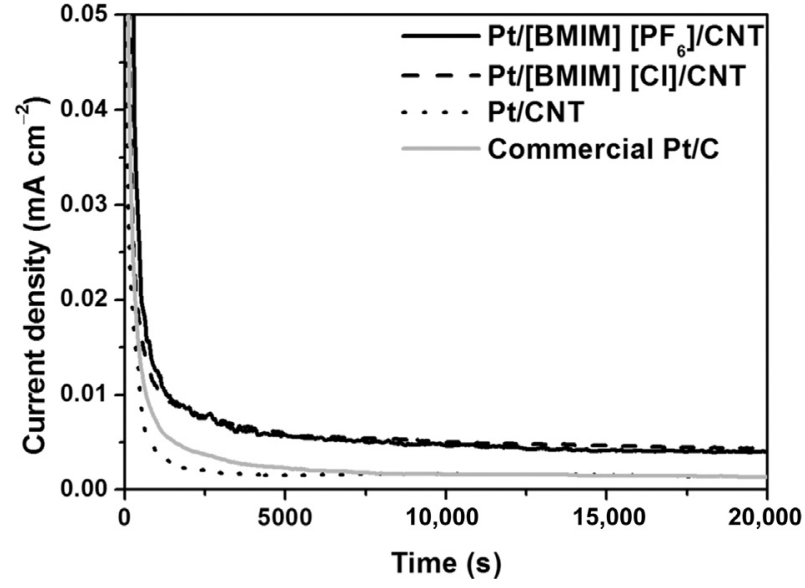

Figure 4. Chronoamperometric curves of $\mathrm{Pt} /\left[\mathrm{BMIM}\left[\mathrm{PF}_{6}\right] / \mathrm{CNT}\right.$, $\mathrm{Pt} /[\mathrm{BMIM}][\mathrm{Cl}] / \mathrm{CNT}, \mathrm{Pt} / \mathrm{CNT}$ nanohybrids, and commercial $\mathrm{Pt} / \mathrm{C}$ $\mathrm{NPs}$ electrodes at a fixed potential of $-0.1 \mathrm{~V} \mathrm{vs}$. $\mathrm{Ag} / \mathrm{AgCl}$ in $0.5 \mathrm{M} \mathrm{KOH}$ containing $0.5 \mathrm{M}$ methanol.

the surfaces of CNTs did play a significant role in stabilizing the Pt NPs.

\section{CONCLUSIONS}

We have demonstrated a facile IL-assisted method for one-pot preparation of $\mathrm{Pt} / \mathrm{IL} / \mathrm{CNTs}$ nanohybrids, with high mass activity and long durability. Among four tested ILs, [BMIM] [Cl] allowed preparation of the Pt/IL/CNTs that provided the highest mass activity. Our result reveals that the counter ions play a significant role in determining the amounts of Pt NPs on the CNT support. In the presence of ILs, small sizes of Pt NPs on the CNT support were formed, leading to greater mass activity than other reported electrodes. Having advantages of good stability, excellent electrocatalytic activities, and cost 
effectiveness, the Pt/[BMIM][Cl]/CNT nanohybrids-modified electrode demonstrates great potential as an efficient anode catalyst for DMFCs.

\section{FUNDING}

This study was financially supported by the Ministry of Science and Technology of Taiwan under contracts NSC 100-2627-M-002-007 and 101-2113-M-002-002-MY3. A. P. Periasamy is grateful to the Department of Chemistry, National Taiwan University for a postdoctoral fellowship under the contract number 101-R-4000.

\section{SUPPLEMENTARY MATERIAL}

Supplementary material is freely available here.

\section{REFERENCES}

[1] Guo S, Dong S, Wang E. Constructing carbon nanotube/Pt nanoparticle hybrids using an imidazolium-salt-based ionic liquid as a linker. Adv Mater. 2010;22:1269-72.

[2] Wu B, Kuang Y, Zhang Y, Zhang X, Chen J. Carbonization of ionic liquid polymer-functionalized carbon nanotubes for high dispersion of PtRu nanoparticles and their electrocatalytic oxidation of methanol. J Mater Chem. 2012;22:13085-90.

[3] Baughman RH, Zakhidov AA, de Heer WA. Carbon nanotubes-the route toward applications. Science. 2002;297:787-92.

[4] Qu L, Dai L. Substrate-enhanced electroless deposition of metal nanoparticles on carbon nanotubes. J Am Chem Soc. 2005; 127:10806-7.

[5] Mackiewicz N, Surendran G, Remita H, Keita B, Zhang G, Nadjo L, et al. Supramolecular self-assembly of amphiphiles on carbon nanotubes: a versatile strategy for the construction of CNT/ metal nanohybrids, application to electrocatalysis. J Am Chem Soc. 2008;130:8110-1.

[6] Wu B, Hu D, Kuang Y, Liu B, Zhang X, Chen J. Functionalization of carbon nanotubes by an ionic-liquid polymer: dispersion of $\mathrm{Pt}$ and PtRu nanoparticles on carbon nanotubes and their electrocatalytic oxidation of methanol. Angew Chem Int Ed. 2009; 48:4751-4.

[7] Kim Y-T, Ohshima K, Higashimine K, Uruga $T$, Takata $M$, Suematsu $\mathrm{H}$, et al. Fine size control of platinum on carbon nanotubes: from single atoms to clusters. Angew Chem Int Ed. 2006;118:421-5.

[8] Zhao Y, Yang X, Zhan L, Ou S, Tian J. High electrocatalytic activity of PtRu nanoparticles supported on starch-functionalized multiwalled carbon nanotubes for ethanol oxidation. J Mater Chem. 2011;21:4257-63.

[9] Wildgoose GG, Banks CE, Compton RG. Metal nanoparticles and related materials supported on carbon nanotubes: methods and applications. Small. 2006;2:182-93.

[10] Xing Y. Synthesis and electrochemical characterization of uniformly-dispersed high loading Pt nanoparticles on sonochemically-treated carbon nanotubes. J Phys Chem B. 2004;108: 19255-9.

[11] Chu H, Shen Y, Lin L, Qin X, Feng G, Lin Z, et al. Ionicliquid-assisted preparation of carbon nanotube-supported uniform noble metal nanoparticles and their enhanced catalytic performance. Adv Funct Mater. 2010;20:3747-52.

[12] He Z, Chen J, Liu D, Zhou H, Kuang Y. Electrodeposition of Pt-Ru nanoparticles on carbon nanotubes and their electrocatalytic properties for methanol electrooxidation. Diamond Relat Mater. 2004;13:1764-70.

[13] Zhao Y, Fan L, Zhong H, Li Y, Yang S. Platinum nanoparticle clusters immobilized on multiwalled carbon nanotubes: electrodeposition and enhanced electrocatalytic activity for methanol oxidation. Adv Funct Mater. 2007;17:1537-41.

[14] Guo D-J, Li H-L. High dispersion and electrocatalytic properties of Pt nanoparticles on SWNT bundles. J Electroanal Chem. 2004;573:197-202.

[15] Liu P. Modifications of carbon nanotubes with polymers. Eur Polym J. 2005;41:2693-703.

[16] Sayes CM, Liang F, Hudson JL, Mendez J, Guo W, Beach JM, et al. Functionalization density dependence of single-walled carbon nanotubes cytotoxicity in vitro. Toxicol Lett. 2006;161:135-42.

[17] Meng L, Fu C, Lu Q. Advanced technology for functionalization of carbon nanotubes. Prog Nat Sci. 2009;19:801-10.

[18] Chen J, Wang M, Liu B, Fan Z, Cui K, Kuang Y. Platinum catalysts prepared with functional carbon nanotube defects and its improved catalytic performance for methanol oxidation. J Phys Chem. B 2006;110:11775-9.

[19] Wu G, Xu, B-Q. Carbon nanotube supported Pt electrodes for methanol oxidation: A comparison between multi- and single-walled carbon nanotubes. J Power Sources. 2007; 174:148-58.

[20] Li W, Liang C, Zhou W, Qiu J, Zhou Z, Sun G, Xin Q. Preparation and characterization of multiwalled carbon nanotube-supported platinum for cathode catalysts of direct methanol fuel cells. J Phys Chem B. 2003;107:6292-9.

[21] Wang Z, Zhang Q, Kuehner D, Xu X, Ivaska A, Niu L. The synthesis of ionic-liquid-functionalized multiwalled carbon nanotubes decorated with highly dispersed $\mathrm{Au}$ nanoparticles and their use in oxygen reduction by electrocatalysis. Carbon. 2008;46:1687-92.

[22] Suarez PAZ, Selbach VM, Dullius JEL, Einloft S, Piatnicki CMS, Azambuja DS, et al. Enlarged electrochemical window in dialkylimidazolium cation based room-temperature air and waterstable molten salts. Electrochim Acta. 1997;42:2533-5.

[23] Zhang J, Bond AM. Conditions required to achieve the apparent equivalence of adhered solid- and solution-phase voltammetry for ferrocene and other redox-active solids in ionic liquids. Anal Chem. 2003;75:2694-702.

[24] Tatumi R, Fujihara H. Remarkably stable gold nanoparticles functionalized with a zwitterionic liquid based on imidazolium sulfonate in a high concentration of aqueous electrolyte and ionic liquid. Chem Commun. 2005;1:83-5.

[25] Verwey EJW, Overbeek JTG. Theory of the stability of lyophobic colloids. New York: Dover Publications; 1999.

[26] Rodríguez-Cabo B, Rodil E, Soto A, Arce A. Preparation of metal oxide nanoparticles in ionic liquid medium. J Nanopart Res. 2012;14:1-10.

[27] Li Z, Jia Z, Luan Y, Mu T. Ionic liquids for synthesis of inorganic nanomaterials. Curr Opin Solid State Mater Sci. 2008;12:1-8.

[28] Zou H, Luan Y, Wang X, Xie Z, Liu J, Sun J, et al. Ionic liquidassisted synthesis of carbon nanotube/platinum nanocomposites. J Nanopart Res. 2012;14:1-10.

[29] Sharma S, Ganguly A, Papakonstantinou P, Miao X, Li M, Hutchison JL, et al. Rapid microwave synthesis of CO tolerant reduced graphene oxide-supported platinum electrocatalysts for oxidation of methanol. J Phys Chem C. 2010;114: 19459-66.

[30] Li Y, Gao W, Ci L, Wang C, Ajayan PM. Catalytic performance of Pt nanoparticles on reduced graphene oxide for methanol electro-oxidation. Carbon. 2010;48:1124-30.

[31] Yang J, Deivaraj TC, Too H-P, Lee JY. Acetate stabilization of metal nanoparticles and its role in the preparation of metal nanoparticles in ethylene glycol. Langmuir. 2004;20:4241-5.

[32] Liu Y, Huang Y, Xie Y, Yang Z, Huang H, Zhou Q. Preparation of highly dispersed CuPt nanoparticles on ionic-liquid-assisted graphene sheets for direct methanol fuel cell. Chem Eng J. 2012; 197:80-7. 
[33] Halder A, Sharma S, Hegde MS, Ravishankar N. Controlled attachment of ultrafine platinum nanoparticles on functionalized carbon nanotubes with high electrocatalytic activity for methanol oxidation. J Phys Chem C. 2009;113:1466-73.

[34] Zhang H, Cui H. Synthesis and characterization of functionalized ionic liquid-stabilized metal (gold and platinum) nanoparticles and metal nanoparticle/carbon nanotube hybrids. Langmuir. 2009;25:2604-12.

[35] Ago H, Kugler T, Cacialli F, Salaneck WR, Shaffer MSP, Windle $\mathrm{AH}$, et al. Work functions and surface functional groups of multiwall carbon nanotubes. J Phys Chem B. 1999;103:8116-21.

[36] Díaz J, Paolicelli G, Ferrer S, Comin F. Separation of the $\mathrm{sp}^{3}$ and $\mathrm{sp}^{2}$ components in the $\mathrm{C}_{1 \mathrm{~s}}$ photoemission spectra of amorphous carbon films. Phys Rev B. 1996;54:8064-9.

[37] Wang X, Fulvio PF, Baker GA, Veith GM, Unocic RR, Mahurin SM, et al. Direct exfoliation of natural graphite into micrometre size few layers graphene sheets using ionic liquids. Chem Commun. 2010;46:4487-9.

[38] Xu F, Minniti M, Barone P, Sindona A, Bonanno A, Oliva A. Nitrogen doping of single walled carbon nanotubes by low energy ion implantation. Carbon. 2008;46:1489-96.

[39] Yu P, Lin Y, Xiang L, Su L, Zhang J, Mao L. Molecular films of water-miscible ionic liquids formed on glassy carbon electrodes: characterization and electrochemical applications. Langmuir. 2005;21:9000-6.

[40] Liu N, Luo F, Wu H, Liu Y, Zhang C, Chen J. One-step ionic-liquidassisted electrochemical synthesis of ionic-liquid-functionalized graphene sheets directly from graphite. Adv Funct Mater. 2008;18:1518-25.

[41] Lin Z-H, Shih Z-Y, Tsai H-Y, Chang H-T. Gold/platinum nanosponges for electrocatalytic oxidation of methanol. Green Chem. 2011;13:1029-35.

[42] Tan Y, Xu C, Chen G, Zheng N, Xie Q. A graphene-platinum nanoparticles-ionic liquid composite catalyst for methanoltolerant oxygen reduction reaction. Energy Environ Sci. 2012;5 6923-7.

[43] Liu Y, Huang Y, Xie Y, Yang Z, Huang H, Zhou Q. Preparation of highly dispersed $\mathrm{CuPt}$ nanoparticles on ionic-liquid-assisted graphene sheets for direct methanol fuel cell. Chem Eng J. 2012; 197:80-7.

[44] Wu B, Hu D, Kuang Y, Liu B, Zhang X, Chen J. Functionalization of carbon nanotubes by an ionic-liquid polymer: dispersion of $\mathrm{Pt}$ and PtRu nanoparticles on carbon nanotubes and their electrocatalytic oxidation of methanol. Angew Chem Int Ed. 2009;48:4751-4.

[45] Yu H-E, Scott K, Reeve R-W. A study of the anodic oxidation of methanol on $\mathrm{Pt}$ in alkaline solutions. J Electroanal Chem. 2003;547:17-24.

[46] Zhang J, Huang M, Ma H, Tian F, Pan W, Chen S. High catalytic activity of nanostructured $\mathrm{Pd}$ thin films electrochemically deposited on polycrystalline $\mathrm{Pt}$ and $\mathrm{Au}$ substrates towards electro-oxidation of methanol. Electrochem Commun. 2007;9:1298-304.

[47] Markovic N, Ross P-N. The effect of specific adsorption of ions and underpotential deposition of copper on the electro-oxidation of methanol on platinum single-crystal surfaces. J Electroanal Chem. 1992;330:499-520.

[48] Yang L, Hu C, Wang J, Yang Z, Guo Y, Bai Z, et al. Facile synthesis of hollow palladium/copper alloyed nanocubes for formic acid oxidation. Chem Commun. 2011;47:8581-3.
[49] Cochell T, ManthViram A. Pt@ $\mathrm{Pd}_{\mathrm{x}} \mathrm{Cu}_{\mathrm{y}} / \mathrm{C}$ Core-shell electrocatalysts for oxygen reduction reaction in fuel cells. Langmuir. 2011;28:1579-87.

[50] Hsin YL, Hwang KC, Yeh C-T. Poly(vinylpyrrolidone)-modified graphite carbon nanofibers as promising supports for $\mathrm{PtRu}$ catalysts in direct methanol fuel cells. J Am Chem Soc. 2007;129:9999-10010.

[51] Zhao M, Li J, Song Z, Desmond R, Tschaen DM, Grabowski EJJ, et al. A novel chromium trioxide catalyzed oxidation of primary alcohols to the carboxylic acids. Tetrahedron Lett. 1998;39: 5323-6.

[52] Keresszegi C, Ferri D, Mallat T, Baiker A. Unraveling the surface reactions during liquid-phase oxidation of benzyl alcohol on $\mathrm{Pd} /$ Al203: an in situ ATR-IR study. J Phys Chem B. 2004;109: 958-67.

[53] Abad A, Concepción P, Corma A, GaVrcía H. A collaborative effect between gold and a support induces the selective oxidation of alcohols. Angew Chem Int Ed. 2005;44:4066-9.

[54] Choudhary VR, Dumbre DK, Bhargava SK. Oxidation of benzyl alcohol to benzaldehyde by tert-butyl hydroperoxide over nanogold supported on $\mathrm{TiO}_{2}$ and other transition and rare-earth metal oxides. Ind Eng Chem Res. 2009;48:9471-8.

[55] Li J, Lin X. A composite of polypyrrole nanowire: platinum modified electrode for oxygen reduction and methanol oxidation reactions. J Electrochem Soc. 2007;154:B1074-B9.

[56] Anderson JL, Armstrong DW, Wei G-T. Ionic liquids in analytical chemistry. Anal Chem. 2006;78:2892-902.

[57] Xu C, Liu Y, Wang J, Geng H, Qiu H. Nanoporous PdCu alloy for formic acid electro-oxidation. J Power Sources. 2012;199: 124-31.

\section{COMPETING INTERESTS}

The authors declare no competing financial interest.

\section{PUBLISHING NOTES}

(C) 2015 Lin et al. This work has been published open access under Creative Commons Attribution License CC BY 4.0, which permits unrestricted use, distribution, and reproduction in any medium, provided the original work is properly cited. Conditions, terms of use and publishing policy can be found at www.scienceopen.com.

Please note that this article may not have been peer reviewed yet and is under continuous post-publication peer review. For the current reviewing status please click here or scan the QR code on the right.

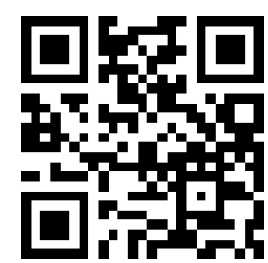

